\title{
NUMERICAL AND EXPERIMENTAL BUCKLING ANALYSIS OF CRANE GIRDER
}

\author{
Ashutosh Kumar', Rachayya R. Arakerimath ${ }^{2}$ \\ ${ }^{1}$ ME Student, Department of Mechanical Engineering, Alard College of Engineering \& Management, Pune, India \\ ${ }^{2}$ Professor, Department of Mechanical Engineering, G.H. Raisoni COEM Pune, India, India
}

\begin{abstract}
Generally structural components are subjected to Complex loadings in their working life. These structure must be capable of taking the desired load. Buckling is one of the important parameter which needs to be considered separately as it may cause the complete structure to fail. Plate buckling causes much problem in Bridge girder of EOT Crane; designers are increasing plate thickness of girder to avoid plate buckling which further increases the weight \& cost of crane. But instead of increasing the plate thickness of compressed plate, its stability can be increased four times more by adding a suitable stiffener section along longitudinal direction which bisect the plate. Detail theory \& example of plate buckling without stiffener \& with stiffener is discussed. Manual \& finite element analysis report for plate buckling is presented to reduce overall weight \& cost of bridge girder of EOT Crane. Results obtained from finite element analysis, Manual calculations and Experimental analysis are compared \& presented in table.
\end{abstract}

Keywords: Aspect Ratio, Buckling Analysis, Stiffened Plate, Dynamic Load, Buckling.

\section{INTRODUCTION}

The main structural components used for box girders, bridges, plate girders, and platforms of offshore structures, shipbuilding and aircraft industries, is thin steel plates. For the purpose of lighten the structural systems and come up with an economy design, plates shall be optimize as maximum as possible. As like, a long slender columns when undergo instability in the form of buckling, steel plates under compression also tend to buckle out of their plane. Because of, the thinness of these structures; buckling is often the controlling failure mode.

Plate stability causes much problem in Bridge girder of EOT Crane; we will reduce weight of Bridge girder of EOT crane

\section{NEED OF RESEARCH}

Snapshot of typical plate buckling cases in bridge girder of EOT crane are as per below.

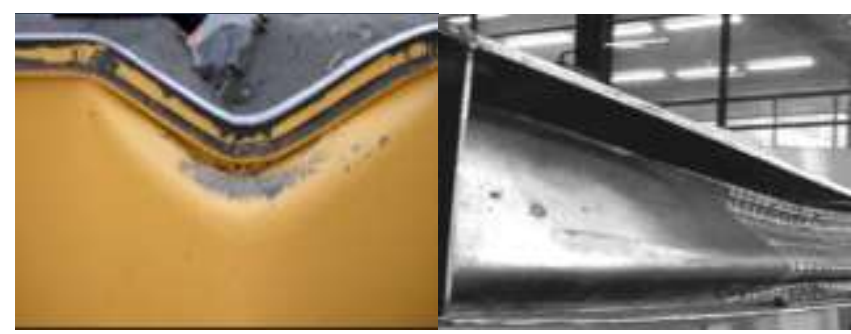

Figure-1 Buckled web of box and I beam girder

Above shown girder is an I-section girder whose web got buckled after load application. The section was enough to carry the load as far as normal and shear stresses are concerned. This raised an alarm that what shall be done to avoid future failures as exact process to calculate and avoid this error was not known.

\section{LITERATURE REVIEW}

J Rhodes [1], presented a paper on the buckling and post buckling behavior of thin plates. It has made a somewhat brief and superficial study of plate element and structure behavior when subjected to local buckling. The author has made a detailed study of all the process being followed till now to understand the plate behavior till now. Still it is clear that there are much more to learn about it.

J Rhodes [2], presented a paper on the buckling of thin plate and early work on rectangular tube. He performed extensive work on the buckling of tubular structure. Post buckling behavior of the tubular thin tube structure was also detailed. Analysis of various sections such as Z,C,and $\mathrm{H}$ sections were done based on previous study. Elastic analysis of plated were performed with simply supported unloaded end and corresponding load deflection curve were outlined. Plastic mechanism analysis were also performed and corresponding constant values were created for Empirical.

N. Raghu Prasad, Jeeoot Singh [3], presented a paper on the buckling of plates with cutout. FEA methods were used to analyze the buckling of these plates. These plates were having simply supported ends. Various method of meshing were used to get optimized result. This analysis was further extended to the study of plate with partial edge compression. Partial edge compression were applied in such a way that the total load on the plate remains same. It was concluded in the result that the pattern of stress were varying by small amount for a plate with and without cutout. 
Ali Reza Pouladkhan, Jalil Emadi, Majid Safemehr [4], presented a paper on numerical study of the buckling of thin plates. Equilibrium equation analysis was used to derive the buckling load equation. Based on the buckling load equation buckling load was calculated. This exercise was performed for simply supported rectangular plate. The results were further cross verified by using FEA software. Abacus software was used to do the analysis. Various meshing techniques were used to get the optimized results. Shell elements were used to do the analysis. The numerical solution and FEA solution both were acceptable from matching to each other.

Sang-Rai Cho, Hyun-seung Lee [5], presented a paper for stiffened plate subjected to lateral collision. This paper was basically useful for the ship structure where the plate panels were subjected to lateral loads. Lateral collision experiments were performed on 33 stiffened plates and corresponding results were tabulated. The test model was created with strain gauge located on them. The striker was also prepared with angle welded to it to strike on the localized area. The purpose was to get the pattern of plate buckling because of it. Analytical method was used for further tabulation of kinetic energy and potential energy stored in it.

Ghania lkhenazen, Messaoud Saidani [6], presented a paper on buckling analysis of an isotropic plate which was subjected to in plane patch loading. Total energy concept was being utilized initially which was later analyzed with FEA. Eight nodded quadrilateral element was used for FEA. Based on analysis charts were produced for buckling factor vs aspect ratio. Similar charts were produced for span to width ratio to buckling factor. Another set of loading was used where the loading pattern was point load. Similar graphs were presented as for earlier graph.. The results were in good agreement with previous task performed in the same field.

Khosrow Ghavami, Mohammad Reza Khedmati [7], presented a paper on numerical and experimental investigation of stiffened plate under compression loading. This paper presented analysis on the nonlinear analysis of stiffened plate subjected to axial compression load and considering post buckling behavior up to collapse. In order to perform the analysis plates with stiffener in both longitudinal and transversal direction and only in longitudinal direction were considered. Two series of experiments were performed. In the first series of experiment the stiffeners were having rectangular, $\mathrm{L}$ and $\mathrm{T}$ profiles along with their spacing were studied while in second series the stiffener profiles were of rectangular shapes were considered. In order to perform the analysis FEA software was used as Ansys. In order to get the results testing rigs were also used. Various collapse modes were observed.

Richard Villavicencio, Sang-Rai Cho, Carlos Guedes soares [8], presented a paper on deformation process of web of a girder used in hull structure of small tanker when subjected to lateral impact. Scaled model was used for the analysis purpose. The model was having top plate stiffened by stiffeners. Plastic range on the model sheet was experienced by performing two impact velocities of load on it. Results were tabulated out and were further verified by FEA software LS Dyna. The results were in good agreement to each other.

FEM 1.001-1998 standard [9], provides rules \& information about design of competent $\&$ steel structure for EOT Cranes for European country. This standard is international standard \& globally accepted for EOT Crane design Detail design procedure for pate subjected bucking of various loading \& boundary condition is discussed in detail IS 807-2006 [10], provides guideline data for steel structure design for EOT Crane. Various cases subjected to pate bucking is discussed.

\subsection{Outcome of Literature Review}

Buckling of rectangular plates subjected to various boundaries \& loading condition has been a subject of study in solid mechanics for more than a century. Many exact solutions for thin isotropic plates have been developed; Exact and approximate solutions for anisotropic plates and laminated plates have also been derived.

Useful guideline are given in some Indian \& international standard. To avoid buckling designer used to increase the thickness of plate which leads in increasing weight of EOT Crane. But instead of increasing the plate thickness of compressed plate, its stability can be increase $\sim$ four times more by adding at suitable stiffener section along longitudinal direction which bisect the plate.

\section{THEORY FORMULATION}

\subsection{Abbreviations \& Nomenclature:}

Geometric Properties

a Longest Dimension of the plate

b Second Longest Dimension of Plate

t Plate Thickness

$\gamma \quad$ Ratio of Flexural rigidity of plate-stiffener

I Moment of Inertia

$v \quad$ Poisson's ratio

Material Properties and Stress Parameters

$\sigma_{1 \mathrm{c}}=\sigma \quad$ Compressive stress

$\tau_{x y}=\tau \quad$ Shear Stress

$\sigma_{\text {erit }} \quad$ Critical Buckling stress

$\sigma_{\mathrm{cr}}^{\mathrm{W}} \quad$ Critical Bending stress

$\tau_{\mathrm{cr}}^{W} \quad$ Critical Shear stress

$\psi \quad$ Stress ratio factor

General Parameters 
EOT Electrically operated overhead travelling

crane

FEA Finite Element Analysis

UTS Ultimate Tensile Stress

\subsection{Basic Theory}

Below shown figure shows the actual condition of crane girder web plate.

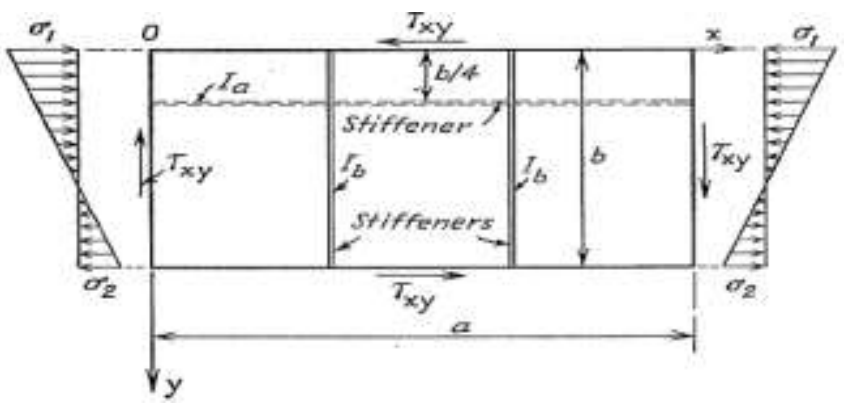

Figure-2 Exact condition of Crane girder web plate [13]

For the above shown figure the Calculation can be performed to get the critical stress as per below mentioned formula [9]

$\sigma_{\text {crit }}=\frac{\sqrt{\sigma^{2}+3 \tau_{x y}^{2}}}{[(1+\psi) * 0.25]\left(\frac{\sigma_{1}}{\sigma_{c r}^{V}}\right)+\left\{\left[0.25 *(3-\psi) *\left(\frac{\sigma_{1}}{\sigma_{c y}^{V}}\right)\right]^{2} *\left(\frac{\tau_{x y}}{\tau_{c r}^{v}}\right)^{2}\right\}^{0.5}}(1)$

The details of the above calculation symbols are elaborated in Appendix-A. The Position shown for the stiffener is derived from the data analysis of the existing cases. It is shown in next section

\section{DATA ANALYSIS}

Based on available stiffener sizes and the web plate of size of 2000x1600x6 thick detailed analysis is done to get the desirable position of stiffener which is shown below:

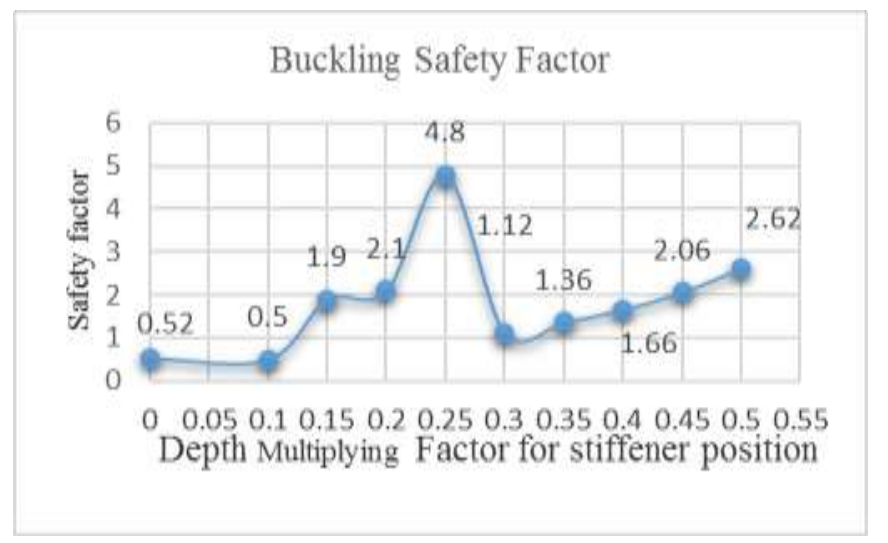

Chart-1 Optimum position of stiffener.
Based on the available sizes of stiffeners and the considered web plate weight and stiffness ratio analysis is also done as shown below:

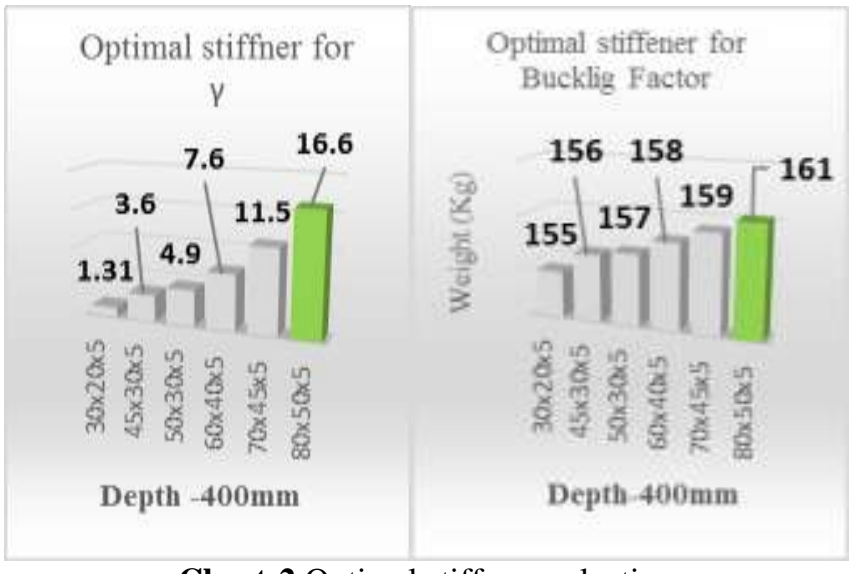

Chart-2 Optimal stiffener selection

Outcome of Data analysis- Optimum position of stiffener is 0.25 times depth of web plate ie $400 \mathrm{~mm}$.

\section{PROBLEM DEFINITION}

In order to certify the concept three cases are considered as per below:-

Case-1: Box Girder with web height of $1600 \mathrm{~mm}$ and effective panel dimension of $2000 \mathrm{~mm}$ will be considered with $6 \mathrm{~mm}$ thickness without any stiffener.

Case-2: Box Girder with web height of $1600 \mathrm{~mm}$ and effective panel dimension of $2000 \mathrm{~mm}$ will be considered with $6 \mathrm{~mm}$ thickness with stiffener $(80 \times 50 \times 5)$ at $400 \mathrm{~mm}$ depth from top compression edge.

Case-3: Box Girder with web height of $1600 \mathrm{~mm}$ and effective panel dimension of $2000 \mathrm{~mm}$ will be considered with $10 \mathrm{~mm}$ thickness without any stiffener.

Problem definition is shown below which will be analyzed for three different cases

Table-1 Input Data

\begin{tabular}{|c|c|c|}
\hline Variant & Unit & Value \\
\hline Safe working Load & ton & 40 \\
\hline Trolley Weight & ton & 12.5 \\
\hline Trolley wheel Base & $\mathrm{mm}$ & 900 \\
\hline Panel Dimension & $\mathrm{mm}$ & $2000 \times 1600 \mathrm{xt}$ \\
\hline Material & & FE-410 \\
\hline Yield Strength & $\mathrm{MPa}$ & 355 \\
\hline Service Factor & & 1.35 \\
\hline Crane Standard & & IS:807,FEM \\
\hline Material Standard & & IS:2062 \\
\hline Note: Value of plate thickness "t" will vary as per Case-1, \\
\hline
\end{tabular}




\section{SIMULATION AND ANALYSIS}

\subsection{Analytical Calculation}

Analytical Calculation is performed based on equation-1.

Table-2 Analytical Result Table

\begin{tabular}{|c|c|c|c|}
\hline Cases & Plate Condition & $\begin{array}{c}\text { Used } \\
\text { Capacity }\end{array}$ & $\begin{array}{c}\text { Buckling } \\
\text { Factor }(\lambda)\end{array}$ \\
\hline Case-1 & $\begin{array}{c}6 \mathrm{~mm} \text { thick Plate Without } \\
\text { Stiffener }\end{array}$ & 2.14 & 0.63 \\
Case-2 & $\begin{array}{c}6 \mathrm{~mm} \text { thick Plate with } \\
\text { stiffener }\end{array}$ & 0.63 & 2.32 \\
\hline Case-3 & $\begin{array}{c}10 \mathrm{~mm} \text { thick Plate without } \\
\text { stiffener }\end{array}$ & 0.98 & 1.39 \\
\hline
\end{tabular}

\subsection{Fea Simulation}

Case-1

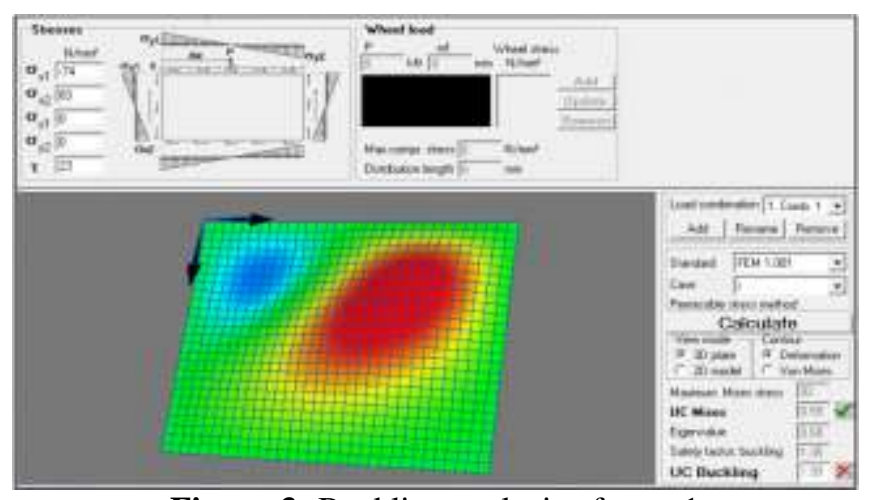

Figure-3: Buckling analysis of case-1

Case-2

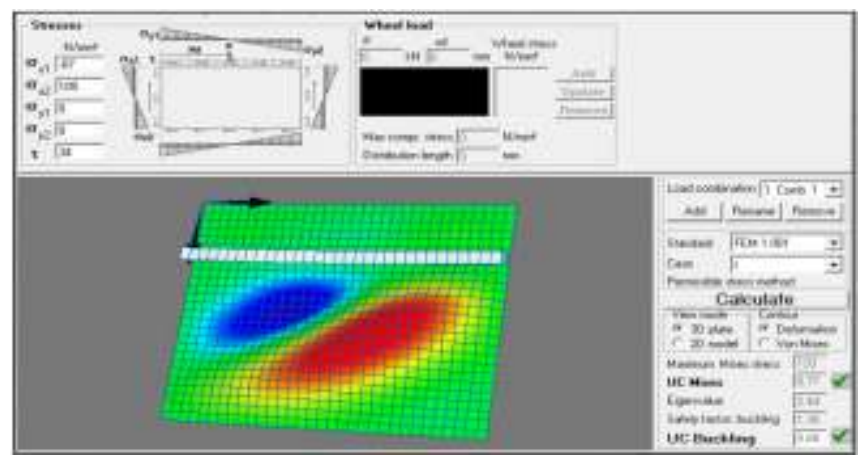

Figure-4: Buckling analysis of case-2

Case-3

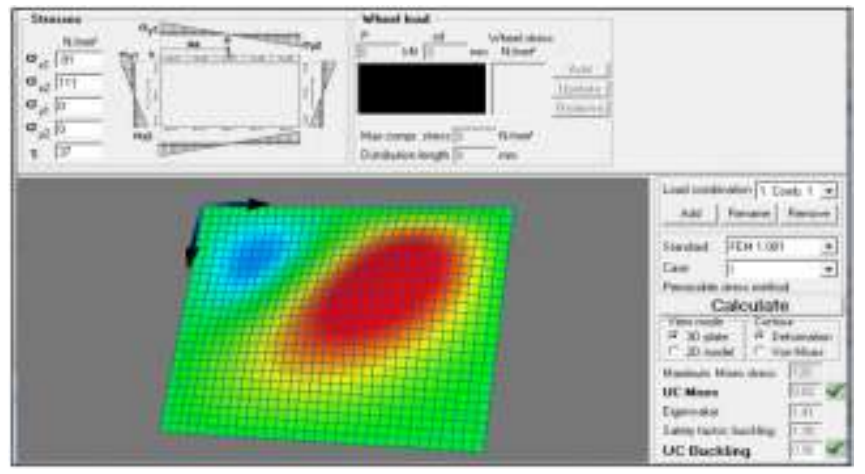

Figure-5: Buckling analysis of case-3
Tabulated result of FEA analysis:

Table-3 FEA Result Table

\begin{tabular}{|l|l|c|c|}
\hline Cases & Plate Condition & $\begin{array}{c}\text { UC } \\
(\text { shall be } \\
<1)\end{array}$ & $\begin{array}{c}\text { Buckling } \\
\text { Factor ( 1) } \\
\text { (shall be >1) }\end{array}$ \\
\hline Case-1 & $\begin{array}{l}\text { 6mm thick Plate Without } \\
\text { Stiffener }\end{array}$ & 1.99 & 0.68 \\
\hline Case-2 & $\begin{array}{l}6 \text { mm thick Plate with } \\
\text { stiffener }\end{array}$ & 0.68 & 2.44 \\
\hline Case-3 & $\begin{array}{l}\text { 10mm thick Plate } \\
\text { without stiffener }\end{array}$ & 0.96 & 1.41 \\
\hline
\end{tabular}

\section{RESULTS AND COMPARISON}

Comparison of FEA \& Analytical Result

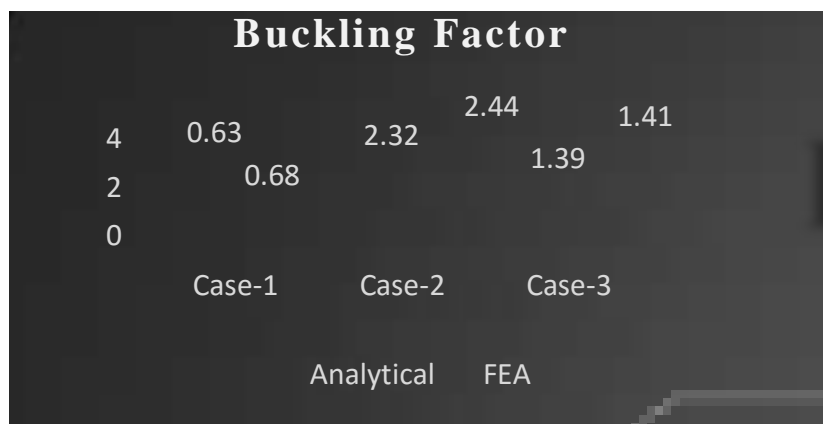

Figure-6: Buckling factor Comparison

From the above figure following points can be concluded:-

- Analytical and FEA results are almost matching with each other with a variation of $6 \%$ max.

- Ideal value of buckling factor shall be greater than 1, case-1 is not satisfying the required criteria.

- Case-2 \& Case-3 satisfies the required buckling factor criteria.

- From the above results Case-2 and Case-3, both satisfies the requirement but it doesn't tell anything about the best option.

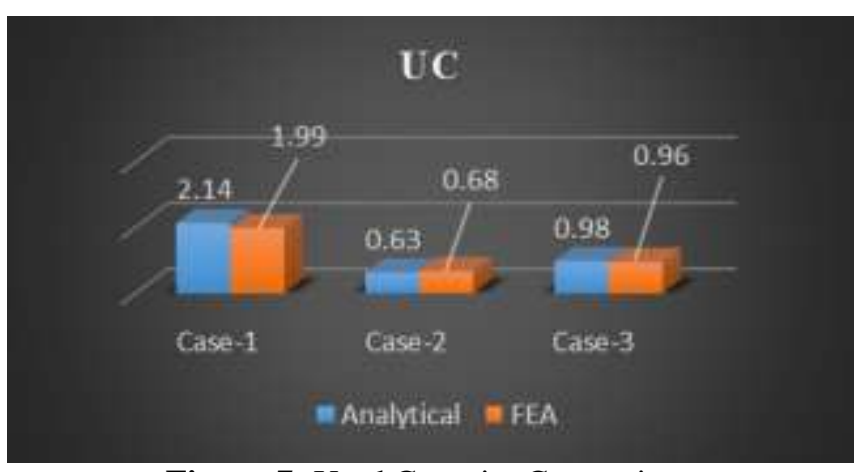

Figure-7: Used Capacity Comparison

From the above figure following points can be concluded:-

- Ideal value of used capacity shall be less than 1 , case- 1 is not satisfying the required criteria.

- Case-2 \& Case-3 satisfies the required used capacity criteria. 
- From the above results Case-2 and Case-3, both satisfies the requirement but it doesn't tell anything about the best option.

In order to find out the optimum option it is required to find out the Price and weight analysis. It is detailed now.

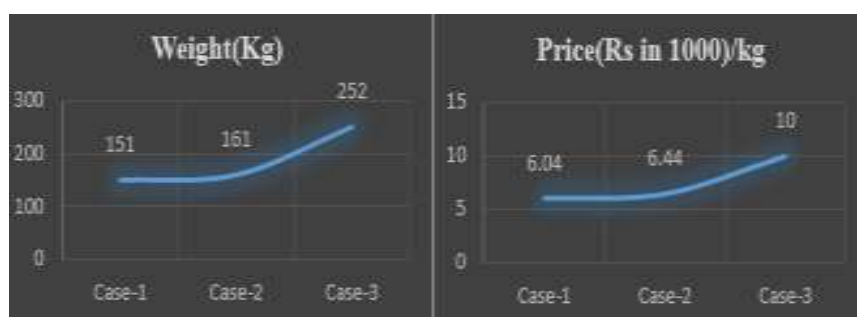

Figure-8: Weight and Price Comparison

From the above figure below mentioned can be concluded:Weight \& Price wise Case-2 is optimum. Although Case-1 has the minimum weight and price but it is of no use as it is not satisfying the buckling criteria. Hence Case-2 is considered for the experimental analysis

\section{EXPERIMENTAL SETUP}

Based on analysis done the manufacturing of box girder was carried on and the experimental setup was prepared. In the experimental setup structural assembly was prepared and kept on stool over the pit. The trolley was placed on the girder to lift the load. The load of 40 ton was already kept in the pit. The experimental setup is shown below.

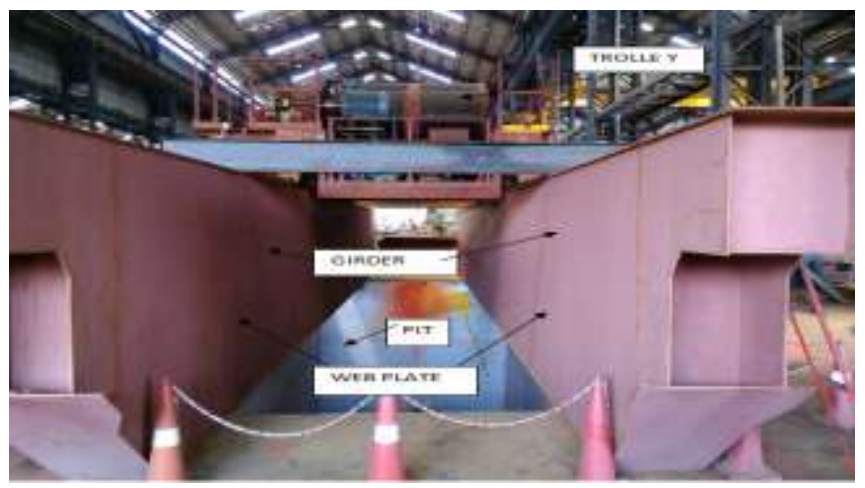

Figure-9: Experimental setup

For data capturing strain gauge and strain indicator was attached to the web as shown below:

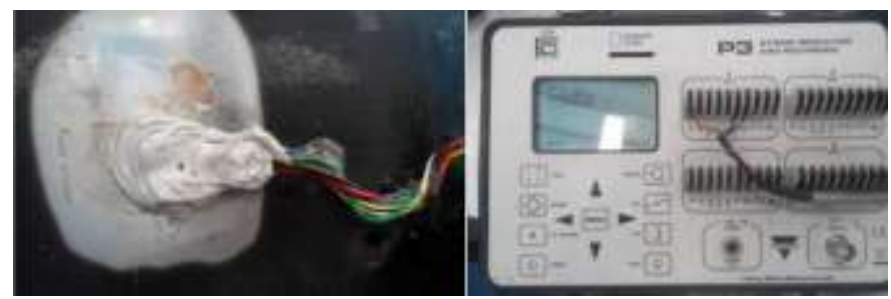

Figure-8: Strain Gauge \& Indicator
Based on the results obtained from the Experimental analysis, comparison was done with analytical and FEA analysis.

\section{- Comparison of FEA, Analytical \& Experimental Result for Case-2}

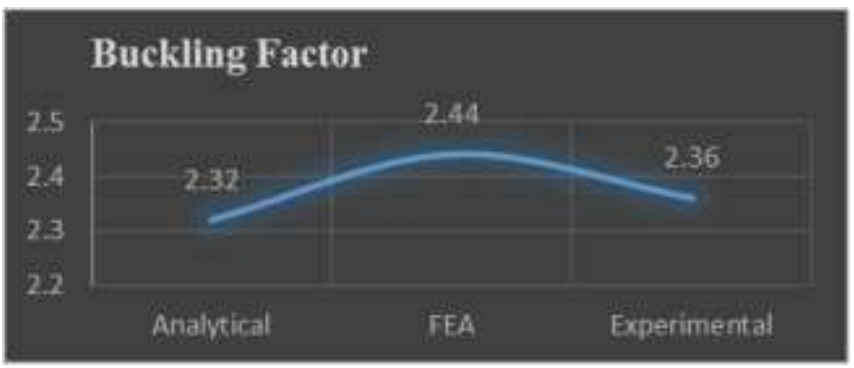

Figure-10: Buckling factor Comparison

Output of the experimental analysis id shown below for the used Capacity.

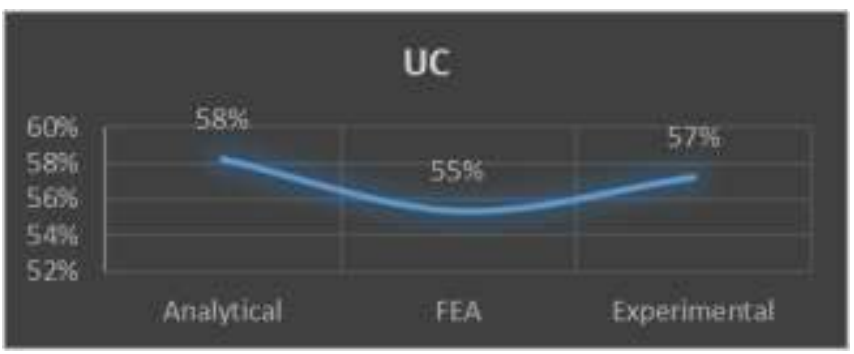

Figure-11: Buckling factor Comparison

From the result shown above following points can be noted:-

(i) Analytical, FEA \& Experimental values are within variation of $10 \%$

(ii) Experimental Value lies in between the Analytical and FEA analysis

\section{CONCLUSION}

Following points can be considered as the overall conclusion of this research:

(i) Output of Analytical, FEA \& Experimental analysis are in quite good argument with each other. The difference in their value is within $10 \%$ limit and is acceptable.

(ii) Overall weight and price can be optimized by addition of stiffener to the existing plate without changing the weight so much.

(iii) There is no need of increasing the thickness of the plate to avoid buckling as the addition of stiffener can avoid the buckling with the same thickness

(iv) Buckling strength of plate structure can be enhanced by addition of stiffener 
Addition of stiffener has not only enhanced the buckling strength but also optimized the weight. Stiffener can be considered as one

\section{ACKNOWLEDGEMENT}

I gratefully acknowledge Mechanical engineering department of ACEM, Pune for technical support and providing the research facilities. I would also like to thank to Dr. S.B. Padwal, Principal (ACEM, Pune) and Prof. V.R. Bajaj, HOD (Mechanical department) for their help and dedication toward my research and related research, also my friends for their directly \& indirectly help, support and excellent cooperation.

\section{REFERENCES}

[1]. J Rhodes, "Some observation of the post-buckling behavior of thin plates and thin walled members", Thin walled structures, 2003, pp. 207-226

[2]. Rhodes J, "Buckling of thin plate members-and early work on rectangular tubes, Elsevier science Ltd, 2002, pp 87-108.

[3]. Prasad N. Raghu, Singh Jeeoot, Buckling analysis of Rectangular plates with cutout and partial edge compression,IARJSET,2015, pp 126-129.

[4]. Ali Reza Pouladkhan, Emadi Jalil, Safemehr Majid, Numerical study of buckling of thin plates, World academy of science, engineering and technology,2011, pp 152-157.

[5]. Sang-Rai Cho, Hyun-seung Lee, Exprimental and analytical investigations on the response of stiffened plates subjected to lateral collision, Sciencedirect,2009, pp 84-95.

[6]. Ghania lkhenazen, Messaoud Saidani, Finite element analysis of linear plates buckling under in-plane patch loading,Journal of constructional steel research 2010, pp 1112-1117.

[7]. Khosrow Ghavami, Mohammad Reza Khedmati, Numerical and Experimental investigations on the compression behavior of stiffened plates, Journal of constructional steel research ,2006, pp 1087-1100

[8]. Richard Villavicencio, Sang-Rai Cho, Carlos Guedes soares, Deformation process of web girders in small-scale tanker double hull structures subjected to lateral impact, ResearchGate,2013, pp-84-111

\section{Reference Standard}

[9] FEM-1.001-European Standard for cranes, 1998(Chapter-2)

[10] IS:807-Structural steel design standard, 2006(Chapter3)

[11] IS:3177-Crane design standard,2006(Chapter-4)

Reference Book

[12] Ventsel Esuard, Krauthammer Theodor, Thin Plates and shell, 2001,pp. 69-76

[13]Timoshenko and Gere, Theory of Elastic stability.,1985(Chapter-9)

[14] Reference Manual -Hyperstudy,2014, pp-104-125 